\title{
Gastric cancer treated with pressurized intraperitoneal aerosol chemotherapy: revising an option for peritoneal carcinomatosis
}

\author{
Filipa Macedo ${ }^{1}$, Kátia Ladeira ${ }^{2,3,4}$, Adhemar Longatto-Filho ${ }^{3,4,5,6}$, Sandra F. Martins ${ }^{3,4,7}$ \\ 1Portuguese Oncology Institute-Coimbra, Coimbra 3000-075, Portugal. \\ ${ }^{2}$ Portuguese Oncology Institute-Lisbon, Lisbon 1099-023, Portugal. \\ ${ }^{3}$ Life and Health Science Research Institute, School of Health Sciences, University of Minho, Braga 4710-057, Portugal. \\ ${ }^{4}$ ICVS/3B's-PT Government Associate Laboratory, Braga/Guimarães, Braga 4710-057, Portugal. \\ ${ }^{5}$ Molecular Oncology Research Center, Barretos Cancer Hospital, Barretos, São Paulo 14784-400, Brazil. \\ ${ }^{6}$ Laboratory of Medical Investigation 14, Faculty of Medicine, University of São Paulo, São Paulo 01246-903, Brazil. \\ ${ }^{7}$ Surgery Department, Coloproctology Unit, Braga Hospital, Braga 4710-243, Portugal.
}

Correspondence to: Dr. Sandra F. Martins, Life and Health Science Research Institute, School of Health Sciences, University of Minho, Braga 4710-057, Portugal. E-mail: sandramartins@med.uminho.pt

\begin{abstract}
How to cite this article: Macedo F, Ladeira K, Longatto-Filho A, Martins SF. Gastric cancer treated with pressurized intraperitoneal aerosol chemotherapy: revising an option for peritoneal carcinomatosis. J Cancer Metastasis Treat 2018;4:8.

http://dx.doi.org/10.20517/2394-4722.2017.72
\end{abstract}

Received: 7 Nov 2017 First Decision: 28 Dec 2017 Revised: 19 Jan 2018 Accepted: 22 Jan 2018 Published: 9 Feb 2018

Science Editor: Masayuki Watanabe Copy Editor: Jun-Yao Li Production Editor: Huan-Liang Wu

\begin{abstract}
Aim: Gastric cancer is the cancer with the highest rate of peritoneal metastization and this type of spread is associated with a higher death rate compared to distant organ metastasis. The systemic chemotherapy has a minimal effect in peritoneal metastasis so new types of treatment have emerged. The authors revised the main studies done in pressurized intraperitoneal aerosol chemotherapy (PIPAC) and presented the main conclusions.
\end{abstract}

Methods: A PubMed search was conducted focusing on PIPAC in gastric cancer. The MeSH database was searched with the terms: "Gastric cancer $[\mathrm{MeSH}]$ and intraperitoneal aerosol chemotherapy".

Results: Seven studies were analyzed. All the studies performed the technique with aerosol of doxorubicin and cisplatin. All cases were well tolerated, with minor adverse effects. Patients presented resolution of their abdominal symptoms and regression of macroscopic carcinomatosis. Cytoreductive surgery or hypertermic intraperitoneal chemotherapy could be performed in some patients with good response to PIPAC. The peritonitis caused by the chemotherapy was well tolerated.

Conclusion: PIPAC can induce remission in end-stage and resistant disease with acceptable side effects, good safety levels for patients and health professionals, and quality of life improvement.

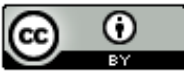

(C) The Author(s) 2018. Open Access This article is licensed under a Creative Commons Attribution 4.0 International License (https://creativecommons.org/licenses/by/4.0/), which permits unrestricted use, sharing, adaptation, distribution and reproduction in any medium or format, for any purpose, even commercially, as long as you give appropriate credit to the original author(s) and the source, provide a link to the Creative Commons license, and indicate if changes were made.

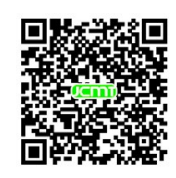


Keywords: Pressurized intraperitoneal aerosol chemotherapy, gastric cancer, peritoneal carcinomatosis

\section{INTRODUCTION}

Gastric cancer accounts for $6.8 \%$ of all cancers and it is the fifth most common cancer worldwide. Moreover, it is the third leading cause of death associated with cancer ${ }^{[1]}$. Gastric cancer has three ways to spread through the body: neoplasic cells could use the lymphatic system to spread to the lymph nodes, the blood stream to spread to distant organs, and the dissemination to peritoneal cavity. This last type of spread is called peritoneal metastatization. Gastric cancer is the cancer with the highest rate of peritoneal metastization and this type of spread is associated with a higher death rate compared to distant organ metastasis ${ }^{[2]}$. Without treatment, the median survival of these patients is 3-5 months.

Gastrectomy combined with D2 lymph node dissection remains the standard of care to manage gastric cancer in advanced stages, however, peritoneal metastases still needs to be optimized. The systemic chemotherapy has a minimal effect in peritoneal metastasis because the barrier between blood and peritoneum do not allow a high concentration of drug in the peritoneum ${ }^{[3]}$. An alternative to systemic chemotherapy consists in surgical removal of affected tissue combined with perioperative chemotherapy that includes: extensive intraoperative peritoneal lavage, neoadjucant intraperitoneal/systemic chemotherapy, hypertermic intraperitoneal chemotherapy (HIPEC), laparoscopic HIPEC and early postoperative intraperitoneal chemotherapy. The problems with these techniques are the need of complete cytoreduction in surgery and they are appropriate only for selected patients ${ }^{[4]}$. Moreover, this treatment is hindered by significant risks and side effects with a 30 -day mortality rate of $5 \%$ in referral centers ${ }^{[5]}$.

Recently, a new alternative therapy has emerged: pressurized intraperitoneal aerosol chemotherapy (PIPAC). This method can only be applied by laparoscopy and it is performed under general anesthesia. In this case, the chemotherapy is dispersed as pressurized aerosol into the peritoneal cavity by minimal invasive techniques, and left acting during $30 \mathrm{~min}$. After this time, the gas is aspired. The recommendation is 3 applications within 3 months. The most frequent adverse effects are fever, abdominal pain and nausea. Complications like infections, herniation or adhesion are uncommon due to minimally-invasive procedure [Figure 1].

\section{METHODS}

A PubMed search was conducted focusing on PIPAC in gastric cancer. The MeSH database was searched with the terms: "Gastric cancer $[\mathrm{MeSH}]$ and intraperitoneal aerosol chemotherapy".

A total of 5 articles were collected. One study was excluded because it is written in Chinese. Then, 3 articles were added because they were recent and pertinent. Ultimately, 7 studies were included in the analysis.

\section{RESULTS}

The main results of the studies are listed in Table $1^{[6-12]}$.

Nadiradze et al. ${ }^{[6]}$ demonstrated that PIPAC is well tolerated but has no effect in patients with synchronous malignant pleural effusion. Twenty-four patients were included in the study, and 60 PIPAC were performed: $71 \%$ of the patients had repeated the procedure; no procedure-related mortality was reported; the mean survival time was 15.4 months; and objective tumor response was observed in 50\% of the patients.

Hübner et al. ${ }^{[7]}$ had used as exclusion criteria for PIPAC the thrombosis of portal vein, intestinal occlusion and some clinical condition that could be a contra-indication for capnoperitoneum. Fifty-eight patients 


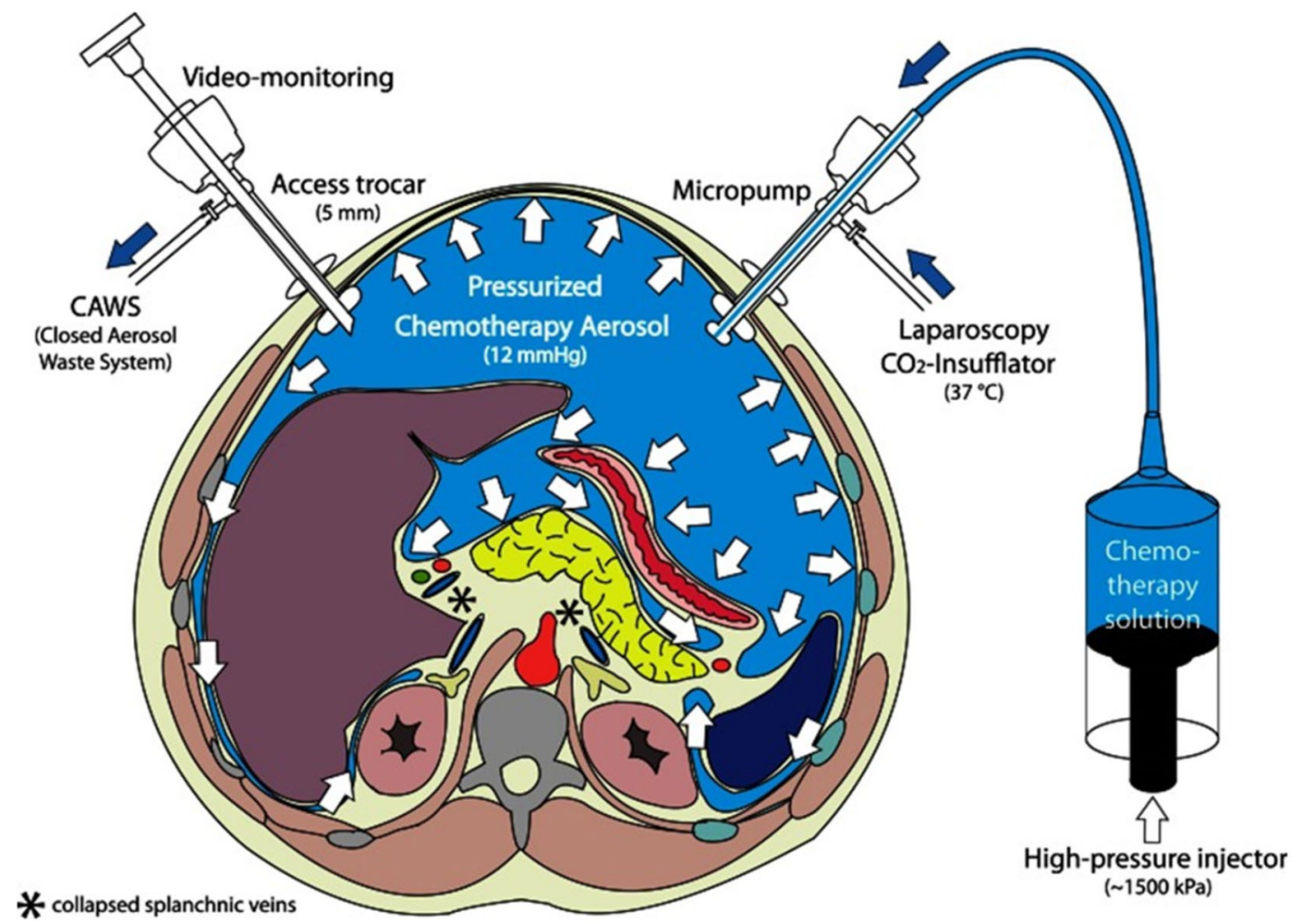

Figure 1. Pressurized intraperitoneal aerosol chemotherapy (PIPAC). Two trocars are inserted into the peritoneal cavity; then $\mathrm{CO}_{2}$ is insufflated in a pressure of $12 \mathrm{mmHg}$. Small tissue samples of the tumor are retrieved (biopsy). Then, the chemotherapy is dispersed as pressurized aerosol inside the peritoneal cavity. At the end of the procedure (30 min), the gas is released over a closed aerosol waste system (CAWS)

were included and 127 PIPAC procedures were performed. One PIPAP was excluded due to incidental small bowel injury.

Tempfer ${ }^{[8]}$ reported some studies, only one with gastric cancer patients. The main emphasis was ovarian cancer. The reported gastric cancer patient was the same patient described in Solass et al. ${ }^{[9]}$ study.

Solass et al ${ }^{[9]}$ followed 3 patients, 1 with gastric cancer, 1 with ovarian cancer and 1 with appendix cancer. In the gastric cancer patient, an early hospital discharge was possible and no severe side effects were observed. Globally, 2 patients showed a complete histological remission and 1 showed a partial remission. It was observed a mean survival of 288 days.

Teixeira Farinha et al.$^{[10]}$ followed 42 patients that underwent PIPAC and evaluated their quality of life during the treatment time and main symptoms.

Girshally et al ${ }^{[11]}$ performed PIPAC in patients with colorectal cancer, appendiceal cancer, ovarian cancer, peritoneal mesothelioma and pseudomyxoma peritoneal as a neoadjuvant treatment in peritoneal metastasis not eligible for cytoreductive surgery and HIPEC. The gastric cancer patients have no extensive peritoneal disease so they were not included.

Alyami et al ${ }^{[12]}$ evaluated the postoperative outcome of 164 procedures of PIPAC using the peritoneal cancer index.

\section{DISCUSSION}

Intraperitoneal chemotherapy is associated to local toxicity due to high drug concentration in peritoneal cavity and the repeated delivery, which leads to chemical peritonitis and a systemic inflammatory response. 
Table 1. Main conclusions of the studies

\begin{tabular}{|c|c|c|c|c|}
\hline Authors & Year & Patients & Aerosol & Conclusion \\
\hline Nadiradze et al. ${ }^{\left[{ }^{\prime}\right]}$ & 2016 & $\begin{array}{l}24 \text { patients with peritoneal metastases } \\
\text { from gastric cancer resistant to systemic } \\
\text { chemotherapy and with no option for } \\
\text { cytoreductive surgery and HIPEC }\end{array}$ & $\begin{array}{l}\text { Doxorubicin } 1.5 \mathrm{mg} / \mathrm{m}^{2} \\
\text { followed by cisplatin } \\
7.5 \mathrm{mg} / \mathrm{m}^{2}\end{array}$ & $\begin{array}{l}\text { Follow-up: } 248 \text { days; } \\
\text { median survival time: } 15.4 \text { months; } \\
\text { survival after follow-up time: } 13 \text { patients; } \\
\text { objective tumor response in } 12 \text { patients; } \\
\text { complete histological regression in } 6 \\
\text { patients }\end{array}$ \\
\hline Hübner et $a l_{.}^{[7]}$ & 2017 & $\begin{array}{l}58 \text { patients with peritoneal disease from } \\
\text { digestive cancer that was persistent or } \\
\text { progressive after prior standard surgical } \\
\text { and/or medical treatment }\end{array}$ & $\begin{array}{l}\text { Doxorubicin } 1.5 \mathrm{mg} / \mathrm{m}^{2} \text { in } \\
\text { combination with cisplatin } \\
7.5 \mathrm{mg} / \mathrm{m}^{2}\end{array}$ & $\begin{array}{l}\text { Intraoperative event rate: } 11 \% \text {; } \\
\text { deaths after the procedure: } 1 \text { patient }\end{array}$ \\
\hline Tempfer $^{[8]}$ & 2015 & 1 patient with peritoneal disease from & Doxorubicin $1.5 \mathrm{mg} / \mathrm{m}^{2}$ & Survival of 109 days; \\
\hline Solass et al. ${ }^{[9]}$ & 2014 & $\begin{array}{l}\text { gastric cancer after gastrectomy and } 2 \\
\text { chemotherapy lines }\end{array}$ & with cisplatin $7.5 \mathrm{mg} / \mathrm{m}^{2}$ & $\begin{array}{l}\text { the patient developed liver and bone } \\
\text { metastases but with no evidence of } \\
\text { peritoneal metastases }\end{array}$ \\
\hline Teixeira Farinha et al. ${ }^{[10]}$ & 2017 & $\begin{array}{l}42 \text { patients: } 21 \text { patients with } \\
\text { chemoresistent isolated peritoneal } \\
\text { carcinomatosis from gynecological } \\
\text { origin, } 14 \text { patients from colorectal origin } \\
\text { and } 3 \text { from gastric origin }\end{array}$ & Not mentioned & $\begin{array}{l}\text { PIPAC had no negative impact on patients' } \\
\text { overall quality of life or in main symptoms; } \\
\text { there was no worse quality of life in PIPAC } \\
\text { patients with high intraperitoneal tumor } \\
\text { load }\end{array}$ \\
\hline Girshally et $a l^{\left[{ }^{[11]}\right]}$ & 2016 & $\begin{array}{l}9 \text { patients with advanced peritoneal } \\
\text { disease no candidates for primary } \\
\text { cytoreductive surgery and HIPEC }\end{array}$ & $\begin{array}{l}\text { Doxorubicin } 1.5 \mathrm{mg} / \mathrm{m}^{2} \\
\text { followed by cisplatin } \\
7.5 \mathrm{mg} / \mathrm{m}^{2}\end{array}$ & $\begin{array}{l}7 \text { patients obtained objective radiological } \\
\text { tumor regression; } \\
8 \text { patients obtained objective major } \\
\text { histological regression }\end{array}$ \\
\hline Alyami et al. ${ }^{[12]}$ & 2017 & $\begin{array}{l}73 \text { patients with non-resectable } \\
\text { peritoneal carcinomatosis ( } 26 \text { from } \\
\text { gastric cancer) }\end{array}$ & $\begin{array}{l}\text { Cisplatin } 7.5 \mathrm{mg} / \mathrm{m}^{2} \\
\text { followed by doxorubicin } \\
1.5 \mathrm{mg} / \mathrm{m}^{2}\end{array}$ & $\begin{array}{l}63.5 \% \text { of patients presented complete } \\
\text { regression of symptoms; } \\
\text { peritoneal cancer index improved in } 64.5 \% \\
\text { of patients }\end{array}$ \\
\hline
\end{tabular}

PIPAC: pressurized intraperitoneal aerosol chemotherapy; HIPEC: hypertermic intraperitoneal chemotherapy

No significant renal toxicity was documented in these studies, however a low-grade liver toxicity was reported in a quarter of patients in Nadiradze et al. ${ }^{[6]}$ study.

Hübner et al. ${ }^{[7]}$ concluded that no learning curve was observed because the operation time did not decrease over time. Some minor complications were observed during this study such as constipation, ileus, transitory neutropenia, urinary retention and wound complications. Looking to these effects, the procedure seems to be safe. Only one patient died due to cardiac arrhythmia.

Tempfer et al. ${ }^{[8]}$ reported that delivering chemotherapy as an aerosol did not represent a risk to health care workers so, it could be used safely in the clinical setting. Moreover, the quality of life improved over 5-6 months.

Solass et al ${ }^{[9]}$ achieved 2 complete remissions and all 3 cases had tumor response. The mean survival of the 3 patients was 288 days, and the gastric cancer patients died 109 days after the procedure.

Teixeira Farinha et al. ${ }^{[10]}$ concluded that PIPAC had no undesirable impact on quality of life of patients with peritoneal carcinomatosis. A shorter hospital stay was associated with patients with better scores at baseline in quality of life. Nondigestive and digestive symptoms remained uncharged after repeated treatments.

Girshally et al. ${ }^{[11]}$ concluded that patients with extensive peritoneal disease that were treated with PIPAC as neoadjuvant therapy had worse prognosis than those treated primarily with citoreductive surgery and HIPEC in limited disease. However, when the cytoreductive surgery and HIPEC were not possible due to extensive disease, PIPAC was successful in diminishing the tumor burden and allowed forward procedures.

Alyami et al ${ }^{[12]}$ found that symptoms related to peritoneal carcinomatosis like ascites, pain or transit disorders were decreased during PIPAC. Some major complications occurred in $9.7 \%$ of the patients and 5 died within 30 days of the PIPAC procedure. 
Searching in the ClinicalTrials.gov registry, we found 1 clinical trial completed in Germany (PIPAC-GA01), but 4 more trials recruiting: 1 in Italy, 1 in Singapore, 1 in Germany and the last 1 in 14 countries. PIPACGA01 is a clinical trial with 35 patients where cisplatin and doxorubicin will be applied in 3 single doses in 6 weeks intervals. The safety and efficacy in terms of the clinical benefit rate will be accessed, but no results were published yet.

At this stage, it is not possible to define indications and contraindications for PIPAC. The authors think that this method could be a good option for patients who have done systemic chemotherapy with severe side effects, patients with renal failure, hepatic failure or patients with cardiac toxicity. On the other hand, it is no option for patients with end-stage disease or malignant pleural effusion.

PIPAC was tested mainly in ovarian cancer, gastric cancer and colon cancer, and it seems feasible in most patients with refractory carcinomatosis of various origins. There were no consistent studies comparing what type of cancer will benefit the most with this technique.

This procedure could be a new palliative treatment option because it may increase quality of life. The next step should be the appliance of this technique in patients in an early stage of peritoneal carcinomatosis to access the efficacy.

\section{DECLARATIONS}

\section{Authors' contributions}

Concept and design of the review, article analysis and interpretation: all authors

Drafting the manuscript: Macedo F, Ladeira K

Manuscript revising: Longatto-Filho A, Martins SF

Approved the final version to be published: all authors

\section{Data source and availability}

All the information analysed during the current study are available in the Pubmed Repository (https://www. ncbi.nlm.nih.gov/pubmed/).

\section{Financial support and sponsorship}

None.

\section{Conflicts of interest}

There are no conflicts of interest.

\section{Patient consent}

Not applicable.

\section{Ethics approval}

Not applicable.

\section{Copyright}

(c) The Author(s) 2018.

\section{REFERENCES}

1. Ferlay J, Soerjomataram I, Dikshit R, Eser S, Mathers C, Rebelo M, Parkin DM, Forman D, Bray F. Cancer incidence and mortality worldwide: Sources, methods and major patterns in GLOBOCAN 2012. Int J Cancer 2015;136:E359-86.

2. Okines A, Verheij M, Allum W, Cunningham D, Cervantes A; ESMO Guidelines Working Group. Gastric cancer: ESMO clinical 
practice guidelines for diagnosis, treatment and follow-up. Ann Oncol 2010;21 Suppl 5:v50-4.

3. Yonemura Y, Endou Y, Sasaki T, Hirano M, Mizumoto A, Matsuda T, Takao N, Ichinose M, Miura M, Li Y. Surgical treatment for peritoneal carcinomatosis from gastric cancer. Eur J Surg Oncol 2010;36:1131-8.

4. Yonemura Y, Canbay E, Endou Y, Ishibashi H, Mizumoto A, Miura M, Li Y, Liu Y, Takeshita K, Ichinose M, Takao N, Hirano M, Sako S, Tsukiyama G. Peritoneal cancer treatment. Expert Opin Pharmacother 2014;15:623-36.

5. Gill RS, Al-Adra DP, Nagendran J, Campbell S, Shi X, Haase E, Schiller D. Treatment of gastric cancer with peritoneal carcinomatosis by cytoreductive surgery and HIPEC: a systematic review of survival, mortality, and morbidity. J Surg Oncol 2011;104:692-8.

6. Nadiradze G, Giger-Pabst U, Zieren J, Strumberg D, Solass W, Reymond MA. Pressurized intraperitoneal aerosol chemotherapy (PIPAC) with low-dose cisplatin and doxorubicin in gastric peritoneal metastasis. J Gastrointest Surg 2016;20:367-73.

7. Hübner M, Grass F, Teixeira-Farinha H, Pache B, Mathevet P, Demartines N. Pressurized intraperitoneal aerosol chemotherapy practical aspects. Eur J Surg Oncol 2017;43:1102-9.

8. Tempfer C. Pressurized intraperitoneal aerosol chemotherapy as an innovative approach to treat peritoneal carcinomatosis. Med Hypotheses 2015;85:480-4

9. Solass W, Kerb R, Mürdter T, Giger-Pabst U, Strumberg D, Tempfer C, Zieren J, Schwab M, Reymond MA. Intraperitoneal chemotherapy of peritoneal carcinomatosis using pressurized aerosol as an alternative to liquid solution: first evidence for efficacy. Ann Surg Oncol 2014;21:553-9.

10. Teixeira Farinha H, Grass F, Kefleyesus A, Achtari C, Romain B, Montemurro M, Demartines N, Hübner M. Impact of pressurized intraperitoneal aerosol chemotherapy on quality of life and symptoms in patients with peritoneal carcinomatosis: a retrospective cohort study. Gastroenterol Res Pract 2017;2017:4596176.

11. Girshally R, Demtröder C, Albayrak N, Zieren J, Tempfer C, Reymond MA. Pressurized intraperitoneal aerosol chemotherapy (PIPAC) as a neoadjuvant therapy before cytoreductive surgery and hyperthermic intraperitoneal chemotherapy. World J Surg Oncol 2016;14:253.

12. Alyami M, Gagniere J, Sgarbura O, Cabelguenne D, Villeneuve L, Pezet D, Quenet F, Glehen O, Bakrin N, Passot G. Multicentric initial experience with the use of the pressurized intraperitoneal aerosol chemotherapy (PIPAC) in the management of unresectable peritoneal carcinomatosis. Eur J Surg Oncol 2017;43:2178-83. 